Parts of the book are more valuable than others, and some original work of the authors on bactericidal properties of skin, very detailed changes reported in bacterial flora, and some observations on local hypersensitivity phenomena are particularly interesting. There are also some instructive experiments on the changes induced in the antigenic structure of tissues following irradiation and some unexpected hypotheses as to the immunological nature of radiation sickness.

This latter antedates most of the work carried out in the Western world on auto-immune diseases, and it is probable that the techniques developed for these studies have since been applied to the hypothesis raised by the authors. The results would be of great interest.

That the book fails to read easily is probably not the fault of the translators, as each paragraph runs smoothly in itself. Rather it is more the result of the review of a vast amount of information which forces the authors into dwelling briefy on a great diversity of material.

The absence of information on the immunological status of established chimeræ and the changes in circulating antibodies reflect both the different direction Soviet research is taking and the original date of publication (1958) - the most recent reference to the British and American literature is 1956 . None the less, the overall picture, if not complete, is extremely impressive and helpful, as it supplies information in many fields where we are largely ignorant. It is to be hoped that there will be more such interchanges of information, which, if reported in similar detail, should be of immense value to workers in these fields.

\section{Progress in Medical Genetics, Vol. I}

Edited by A. G. Steinberg, PH.D. Pp. viii $+34 \mathrm{I}$, illustrated. New York and London: Grune and Stratton. 1961. \$9.75.

Progress in medical genetics has been extremely rapid over the last decade. The reasons for these advances are varied and numerous; the initial impetus, however, probably came from the demonstration of the genetic determination of the blood groups in man and of their variable distribution among the populations of the world.

With the growing interest in human genetics it has become almost impossible to keep abreast of the rapid advances which have been made in the various fields. This volume is aimed at presenting up-to-date reviews of these topics in a manner which is acceptable to the clinician, the geneticist and the student. It is probable that each of these academic groups will find some chapters of interest, for the topics reviewed include both general and more specialized subjects.

The study of mutation is undoubtedly one of the most important fields of human genetic research and also one of the most difficult fields in which to gain useful information. Dr. C. F. Crow presents a generalized survey of this topic, with special emphasis on the problem of detection of mutants and estimation of the mutation rate. Unfortunately, however, very little space is devoted to the factors affecting mutation rate, factors which will be of increasing importance in this atomic era.

Professor J. B. S. Haldane presents a very readable account of the processes of natural selection in man. He discusses the action of selection, including medical practice, in altering gene frequencies in relation to such factors as the breeding system and population fitness. Professor Haldane concludes that "we now know less about natural selection in man than I knew 30 years ago'! Perhaps this is but a reflection of his preference" to live in a country where the assortment of human genes differs from that of Europe and North America to a country with good libraries'!

Knowledge of experimental embryology and developmental genetics is rapidly increasing. As yet most of the advances are too recent to assess their implications with respect to mankind. Professor F. Clarke Frazer presents an up-to-date review of this field with special reference to congenital malformations and of their possible relationship to medical genetics.

A volume of this nature would be incomplete without some chapters devoted to human blood groups; Dr. C. A. Clarke lucidly reviews the subject of blood groups and human disease, whilst Drs. Levene and Rosenfield deal with the subject of ABO incompatibility. Both of these otherwise excellent chapters are, however, marred by several minor faults, such as the failure of the total $\chi^{2}$ in Table 2 of Clarke's chapter to agree with that presented in the text. Moreover, in the chapter by Levene and Rosenfield two tables appear which are not even referred to in the text.

The remaining chapter devoted to the genetics of blood groups is a very lengthy review by Drs. Rucknagel and Neel of the hæmoglobinopathies. All of the many aspects of the human hæmoglobins are considered in somewhat excessive detail. Unfortunately, no summary of the information is given, so that readers with only a cursory interest in this field are obliged to plough through over ros pages of rather heavy text.

The final two chapters are devoted to subjects which will become of increasing importance as techniques for the analysis of genetic phenomena in man. Professor Newton E. Morton considers the morbidity of children from consanguineous marriages and the genetic information which may be gained from such a study, whilst Dr. Ferguson-Smith discusses chromosomes and human disease. It is this last subject which has perhaps the most popular appeal to both the clinician and geneticist, for it is in this field that some of the most spectacular discoveries in human cyto-genetics have been made in recent years.

Dr. Ferguson-Smith presents a concise review of the literature and relevant background information. But in doing so he states that genetic phenomena which have recently been found in man may now also be found in Drosophila. In truth, they have, in fact, long been known in Drosophila. This final chapter is further marred by the contents of Table 5 being clearly inconsistent with the actual information, even though it is presented correctly in the text.

The book itself is well produced and edited except for a few minor printing errors, a striking one being found in the list of contents, where the eighth chapter is described as: 8. CHOMOSOMES AND HUMAN DISEASE.

It is to be hoped that further volumes in this series will appear at not too infrequent intervals.

\section{The Premature Baby}

V. Mary Crosse, O.B.E., M.D., D.P.H., M.M.S.A., D.o.R.C.o.G. Pp. viii +266 , illustrated. London: J. \& A. Churchill. 1960. $24 s$.

The revised and reprinted version of this well-known little book will be, without doubt, popular with students and those concerned with the management of premature babies, as it has been so notably over the last 16 years. The work, now in its fifth edition, has once again been brought up to date and this has entailed the complete rewriting of several parts. The book, nevertheless, remains of modest size which has always been one of its attractions. The author has had an unrivalled experience with these small babies over a period of some 